\title{
Optimization of Reaction Conditions for Synthesis of MOF-5 using Solvothermal Method
}

\author{
Tri Ana Mulyati ${ }^{1}$, Ratna Ediati ${ }^{1}$, and Muhammad Nadjib ${ }^{1}$
}

\begin{abstract}
MOF-5 (metal-organic frameworks-5) have been synthesized using solvotermal method in which reaction mixtures of zinc nitrate hexahydrate and benzenedicarboxylic acid in dimethylformamide were heated at various heating temperatures and times in order to obtain the best reaction conditions for the synthesis of MOF-5. The heating temperatures used were 105, 120 and $140{ }^{\circ} \mathrm{C}$, respectively with heating times of 12-144 hours. Determination of the best reaction conditions was based on the observation of phase purity and crystal morphology of MOF-5 using XRD and SEM. The characterization results showed that optimization of MOF-5 crystals were obtained when the reaction mixtures were heated at $105{ }^{\circ} \mathrm{C}$ for $144 \mathrm{~h}, 120^{\circ} \mathrm{C}$ for $24 \mathrm{~h}$ and $140{ }^{\circ} \mathrm{C}$ for $12 \mathrm{~h}$. The maximum weight of MOF-5 crystal was generated from reaction mixture heated at $120^{\circ} \mathrm{C}$ for $72 \mathrm{~h}$.
\end{abstract}

Keywords-MOF-5, solvothermal, synthesis, optimization.

\section{INTRODUCTION}

$\mathrm{M}$ etal-organic frameworks 5 (MOF - 5) are new type materials in which the metal ion acts as a coordinating center and associated with a variety of polyatomic organic compounds to form threedimensional structures. By changing the metal ions and ligands used, material with variety in porosity, surface area and pore size can be obtained [1]. One type of MOFs which is still intensively investigated to date is MOF-5. The advantages of MOF-5 include a large surface area, high porosity and low-cost and readily available raw materials [2]. MOF-5, with molecular formula of $\mathrm{Zn} 4 \mathrm{O}(\mathrm{BDC}) 3$, has been synthesized from $\mathrm{Zn}(\mathrm{NO} 3) 2.6 \mathrm{H} 2 \mathrm{O}$ (zinc nitrate hexahydrate) as the inorganic material associated with H2BDC (1,4-benzene dicarboxylic acid) as the organic linker and DEF (N'Ndiethylformamid) or DMF (N'N-dimethylformamid) as solvents. The DEF is preferred as a reaction solvent eventhough the DMF can be used as a substitute for the equivalent phase but get lower quality and cheaper price [3].

Methods for MOF-5 synthesis have been developed with the aim of obtaining materials with high surface area and pore volume. It has been reported that MOF-5 has been synthesized by use of solvotermal method as well as sonochemical [4] and microwave methods [3]. Solvotermal method is widely used as MOF-5 crystals with large surface area crystallinity and pore volume have been produced [5]. The parameters influence. The characteristics of MOF-5 crystals depend on reaction parameters such as reaction temperature, reaction time, ratio of metal / ligand, solvent composition and $\mathrm{pH}$ of the solution [6].

Some researchers have reported the synthesis and characterization of MOF-5 by use of the solvotermal method at various reaction conditions. Biemmi et al . (2009) [7] have synthesized MOF-5 at $110{ }^{\circ} \mathrm{C}$ for 48 hours and the product has a typical diffractogram pattern of MOF-5. Lu et al. (2010) [8] and Son et al . (2010) [4] have reported that MOF-5 crystals with a surface area of

${ }^{1}$ Tri Ana Mulyati, Ratna Ediati, and Muhammad Nadjib are with Departement of Chemistry, Faculty of Mathematic and Science, Institut Teknologi Sepuluh November, Surabaya, 60111, Indonesia.

E-mail: ana12@mhs.chem.its.ac.id; rediati@chem.its.ac.id; nadjib@chem.its.ac.id.
1080 and $3200 \mathrm{~m} 2 / \mathrm{g}$ have been obtained at a heating temperature of $105{ }^{\circ} \mathrm{C}$ for 20 hours and 24 hours respectively. Furthermore, Phan et al. (2010) [9] and Blanita et al. (2011) [2] have shown that higher surface area and pore diameter of MOF-5, i.e. $3846 \mathrm{~m} 2 / \mathrm{g}$ and $18.6 \AA$ as well as $3153 \mathrm{~m} 2 / \mathrm{g}$ and $18.3 \AA$, have been synthesized at $100{ }^{\circ} \mathrm{C}$ for 24 hours and 7 hours, respectively. In addition, Zhao et al. (2011) [10] have also reported the synthesis of MOF - 5 at $130{ }^{\circ} \mathrm{C}$ for 4 hours which produces cubic crystals. The results mentioned above indicate that the heating temperature and time in the synthesis of MOF-5 can affect the characteristics of the obtained MOF-5. Therefore, research on the optimization of reaction conditions for synthesis of MOF - 5 in order to obtain MOF - 5 crystals with the desired characteristics is still required.

Several studies conducted by Orefuwa et al. (2012) [11] , Venna et al. (2010) [12] , and Biemmi et al. (2009) [7] have discussed the optimization of reaction temperatures and times for the synthesis of MOFs. Orefuwa et al. (2012) [11] have reported the effect of reaction temperatures on the structure of IRMOF-8 in which an intermediate phase and other products have been formed when the reaction temperatures of $100{ }^{\circ} \mathrm{C}$ and $150{ }^{\circ} \mathrm{C}$ were used respectively. An evolution of ZIF-8 structure as a function of time has been reported by Venna et al. (2010) [12], i.e. the phase purity of ZIF-8 increased with the increase in reaction time and remained unchanged after 50 minutes, whereas the crystal size of ZIF-8 increased with the increase in reaction time. The research results Biemmi et al. (2009) [7] have shown the evolution of the HKUST-1 structure as a function of temperature despite the formation of metal oxide $\mathrm{Cu} 2 \mathrm{O}$ phase at a temperature of $453 \mathrm{~K}$. In addition, the regularity of morphology of the HKUST- 1 crystals decreased with the increase in reaction temperatures. In the case of MOF-5 synthesis, Choi et al. (2008) [13] have investigated the effect of reaction time on crystallinity of MOF - 5 synthesized by use of microwave method at various reaction time of 15, 30, 45 and 60 min. Diffractogram patterns of MOF - 5 generated from reaction time of 15,45 , and $60 \mathrm{~min}$ showed the highest peak intensity at $2 \theta$ of $9.6^{\circ}$ and $6.8^{\circ}$ when the reaction time was $30 \mathrm{~min}$.

Optimization of the reaction temperatures and times for the synthesis of MOF - 5 by use of solvotermal method has not been reported. Therefore, synthesis of 
MOF - 5 by use of solvothermal methods at various heating temperatures of $105^{\circ} \mathrm{C}, 120^{\circ} \mathrm{C}$ and $140{ }^{\circ} \mathrm{C}$, for various heating times of 12, 24, 36, 48, 72 and 144 hours have been performed in this study. The determination of the optimum reaction conditions for the synthesis has been focused on the observation of phase purity and crystal morphology of MOF - 5 through characterization results by XRD and SEM.

\section{METHOD}

\section{A. Synthesis of MOF-5}

The materials used for the synthesis of MOF-5 include zinc nitrate hexahydrate ( $\mathrm{Zn}(\mathrm{NO} 3) 2.6 \mathrm{H} 2 \mathrm{O}$ SigmaAldrich, 99,0\%), 1,4-benzenedicarboxylic acid (H2BDC Sigma-Aldrich, 99,0\%), N'N-dimethylformamide (DMF, Merck, 99,8\%), chloroform (CHCl3, Merck, 99,9\%), nitrogen, and aquades.

The synthesis of MOF-5 has been carried out by dissolving $6.48 \mathrm{~g}$ of zinc nitrate hexahydrate $(6.1 \mathrm{mmol})$ and $1.188 \mathrm{~g}$ of 1,4-benzenedicarboxylic acid (2.0 mmol) in $180 \mathrm{~mL}$ DMF, then stirred with magnetic stirrer for 30 minutes. The reaction mixture was then transferred into 6 of $50 \mathrm{~mL}$ vial botols with lids, each with a volume of 30 $\mathrm{mL}$, and heated in an oven at $105^{\circ} \mathrm{C}$. Each reaction mixture was removed from the oven at intervals of 12 , 24, 36, 48, 72 and 144 hours, allowed to cool at room temperature. The solvent was then removed from the vial bottles by decantation, the solid was washed by adding $30 \mathrm{~mL}$ of DMF and left for 24 hours. The washing process was repeated twice with chloroform as the solvent. The obtained solid was then dried under vacuum at $60{ }^{\circ} \mathrm{C}$ and stored in a container with a nitrogen atmosphere and weighed. The same process was repeated for the heating temperature of 120 and $140{ }^{\circ} \mathrm{C}$.

\section{B. Characterization}

The crystalline structures of the obtained samples were determined by X-ray diffraction (XRD) by use of a JEOL diffractometer with a $\mathrm{Cu} K \alpha$ radiation $(\lambda=$ $1.54056 \AA$ ) at $40 \mathrm{kV}$ and $30 \mathrm{~mA}$. The diffractograms were recorded with a $2 \theta$ scale of $5-50^{\circ}$ and a scan speed of $0.020 \%$ sec. Surface morphology and the percentage content of elements in the crystals obtained by SEMEDX (SEM - Zeiss EVO MA10).

\section{RESULT AND DISCUSSION}

\section{A. Synthesis of MOF-5 with Solvothermal Method}

The clear solution of ( $\mathrm{Zn}(\mathrm{NO} 3) 2.6 \mathrm{H} 2 \mathrm{O})$ and H2BDC in DMF turned into a mixture of a white solid on the walls and bottom of the bottle vial and clear filtrate (Fig. 1b), (Fig. 1a) after the heating process. After washing and drying process, the white crystals were obtained (Fig. 1c). The weight of the crystals produced at each heating temperature is shown in Figure 2. At a temperature of $105{ }^{\circ} \mathrm{C}$, the weight of the resulting crystals increases with the increase in heating to reach a maximum of 0.53 grams after heating for 144 hours.

However, at the reaction temperatures of $120{ }^{\circ} \mathrm{C}$ and $140{ }^{\circ} \mathrm{C}$, the maximum weight of the obtained crystals were as much as 0.68 grams and 0.61 grams, respectively, at a temperature of $120^{\circ} \mathrm{C}$ for $72 \mathrm{~h}$ and 140 ${ }^{\circ} \mathrm{C}$ for 36 hours. Therefore, reaction conditions that produce crystals most is heating at a temperature of 120 ${ }^{\circ} \mathrm{C}$ for 72 hours (Fig 2).

\section{B. Optimization Optimization Synthesis of MOF-5 on Variation Temperature and Time}

1) Optimization at Temperature $105^{\circ} \mathrm{C}$

Diffractogram pattern of crystals synthesized at $105^{\circ} \mathrm{C}$ for 12-144 hours and simulated diffractogram of MOF-5 are shown in Figure 3.

As is shown in the Figure 3, crystals obtained at heating time for 12 hours (a) has different diffractogram pattern to that of simulated MOF-5 which indicates that MOF-5 crystal has not been formed. When the heating times were increased up to 36 hours, the MOF- 5 crystals have been formed along with the presence of impurities, as indicated from the appearance of small peak at $2 \theta=$ $6.8^{\circ}$ on the diffractograms $\mathrm{b}$ and $\mathrm{C}$. Further increase in the heating time for $48-144$ hours resulted in the formation of crystals with the same diffractogram pattern to that of simulated MOF-5 (Figures 3f). The formation of MOF-5 is indicated by the presence of four peaks at $2 \theta=6.8^{\circ} ; 9.6^{\circ} ; 13.7^{\circ}$ and $15.4^{\circ}$ (Fig. $3 \mathrm{f}$ ) as reported by $\mathrm{Li}$, et al. [5]. The highest crystal weight of $0,5303 \mathrm{~g}$ has been achieved by heating time of $144 \mathrm{~h}$.

2) Optimization at Temperature $120^{\circ} \mathrm{C}$

Diffractogram pattern of crystals synthesized at 120 ${ }^{\circ} \mathrm{C}$ for $12-144$ hours and the simulated diffractogram pattern of MOF-5 are shown in Figure 4. At the heating temperature of $120{ }^{\circ} \mathrm{C}$, MOF-5 crystals have been formed after reaction times of 24 hours as indicated by the appearance of peaks characteristic of MOF-5 at $2 \theta=$ $6.8^{\circ} ; 9.6^{\circ} ; 13.7^{\circ}$ and $15.4^{\circ}$. As can be seen in Figures $4 \mathrm{~b}, \mathrm{c}$ and $\mathrm{d}$, the crystals obtained with heating times of 24 - 144 hours show the same diffractogram pattern to that of simulated MOF-5 (Fig. 4e) [5]. The intensity of the four main peaks, however, decreases with the increase in heating time, which indicates that the crystallinity of the MOF-5 decreases with the increase in heating time. Based on these results, the best heating time at $120^{\circ} \mathrm{C}$ is 24 hours.

3) Optimation at Temperature $140{ }^{\circ} \mathrm{C}$

Diffractogram pattern of crystals synthesized at $140{ }^{\circ} \mathrm{C}$ for 12 - 144 hours and the simulated diffractogram pattern of MOF-5 are shown in Figure 5. In other hand, crystal formed by synthesis at temperature $140{ }^{\circ} \mathrm{C}$ on 12 h. Figure $5 \mathrm{a}$, crystal formed indicate peak characteristic of simulated peak on $2 \theta=6,8^{\circ} ; 9,6^{\circ} ; 13,7^{\circ}$ and $15,4^{\circ}$. This Characteristic peak still appear at difractogram of crystal on synthesis time 24-144 h, despite of the characeristic peak intensity decrase with increasing heating time (Fig. 5b-5e).

This decrease in intensity indicates that the crystallinity of the MOF-5 crystals are lower with increasing synthesis time of 24-144 hours. Therefore, based on the crystallinity of the resulting crystals, long the best heating for the synthesis of MOF-5 at a temperature of $140{ }^{\circ} \mathrm{C}$ is 12 hours.

4) Crystallinity and Morphology of MOF-5

As explained above, the best treatment for the synthesis of MOF-5 is $105{ }^{\circ} \mathrm{C}-144$ hours, $120{ }^{\circ} \mathrm{C}-24$ hours, and $140{ }^{\circ} \mathrm{C}-12$ hours. This treatment was chosen because the resulting crystal diffractogram pattern follows the pattern of simulated diffractogram and has the highest crystallinity. Nevertheless, from a comparison of the three crystals selected diffractogram 
and simulation of MOF-5 (Fig 6), it is seen that the results of treatment Kristal $120^{\circ} \mathrm{C}-24$ hours has the same pattern with the simulated diffractogram MOF-5 (Fig 6b and 6d).

Furthermore, the crystallinity in each diffractogram pattern is calculated based on the number 4 peak area on MOF-5 characteristics analogy with the calculation of peak area were carried out by Jiang et al. (2011) [17]. Crystal with the largest peak area, expressed with $100 \%$ crystallinity, other crystals with a lower peak area, crystallinity is calculated relative to the peak area of the highest value. Crystallinity calculation results of treatment outcome Crystals $105^{\circ} \mathrm{C}-144$ hours (A), 120 ${ }^{\circ} \mathrm{C}$ - 24 hours (B) and $140{ }^{\circ} \mathrm{C}-12$ hours (C) are shown in Table 1 . Crystal with the highest crystallinity resulting from the treatment of $120^{\circ} \mathrm{C}-24 \mathrm{~h}$.

Crystal morphology of MOF-5 synthesized A, B and C and the approximate elemental composition were observed using SEM - EDX, the results of which are shown in Figure 7 -9. From the SEM photograph can be seen that the MOF- 5 crystals A, B and C have the form of a box. This observation is in accordance with SEM photograph MOF-5 has publicated by Li et al., (2009) [5]. Morphological differences between the three crystals synthesized MOF-5 is located on the surface texture. Flat surface morphology with smaller crystal size (85-95 $\mu \mathrm{m})$, indicated by the MOF-5 crystals synthesized at high temperature $\left(140^{\circ} \mathrm{C}\right)$ with a short time (12 hours), as can be seen in Figure 9. Increased long heating at lower temperatures, which is the treatment of $100{ }^{\circ} \mathrm{C}$ $144 \mathrm{~h}$ and $120{ }^{\circ} \mathrm{C}-24 \mathrm{~h}$, resulting in MOF-5 crystals with larger particle size $(250-300 \mu \mathrm{m})$ and the surface morphology is less flat (Fig 7 and 8 ).

When compared with the results of Yang et al. (2011) [18], MOF-5 crystals synthesized at the conditions of $140{ }^{\circ} \mathrm{C}-12 \mathrm{~h}$ have a similar size, which ranges $100-110$ $\mu \mathrm{m}$, while the size of the crystal at $100^{\circ} \mathrm{C}-144 \mathrm{~h}$ and $120^{\circ} \mathrm{C}-24 \mathrm{~h}$ are similar to those reported Mueller et al. (2006) [19] yaitu berkisar (200-250 $\mu \mathrm{m})$.

Elemental composition (wt\%) in MOF-5 A, B and C from EDX results are shown in Figure 7-9 and Table 2. The results obtained from the red circle representing the MOF-5 box.

As is seen, the optimum composition of the $\mathrm{Zn}$ is contained in the treatment of $120^{\circ} \mathrm{C}-48 \mathrm{~h}$, which is $35.50 \mathrm{wt} \%$, whereas treatment with the smallest $\mathrm{Zn}$ composition obtained in the treatment of $140^{\circ} \mathrm{C}-12 \mathrm{~h}$ is $30.13 \mathrm{wt} \%$ (Table 2). Although there are differences, but this difference was only 3-5 wt\% in each treatment. Therefore, it might be concluded that all three selected treatments produced MOF-5 crystals that have formed.

When compared with the elemental composition of the simulation, then a similar treatment is $120^{\circ} \mathrm{C}-24$ hours which is very similar to the simulation code $\mathrm{D}$. This suggests that the formulation of MOF-5 may be formed in this study is Zn4,26O12,8C24H11,3.

\section{CONCLUSION}

Based on the XRD patterns, the optimum treatment obtained at a temperature of $105^{\circ} \mathrm{C}$ was 12 hours, at a temperature of $120^{\circ} \mathrm{C}$ was 48 hours, while at a temperature of $140{ }^{\circ} \mathrm{C}$ was 144 hours. This is shown by the XRD pattern generated according to the XRD patterns simulated MOF-5 and has the highest intensity.
SEM results showed that all three treatments at optimum conditions, ie $105^{\circ} \mathrm{C}-144 \mathrm{~h}, 120^{\circ} \mathrm{C}-24 \mathrm{~h}$, and $140^{\circ} \mathrm{C}$ $12 \mathrm{~h}$ has a morphology that box. The third difference lies in the morphology of the surface texture. In the treatment of $140^{\circ} \mathrm{C}-144$ hours has the smoothest surface texture but very small crystals obtained. In the treatment of 105 ${ }^{\circ} \mathrm{C}$ - 12 hours crystalline MOF-5 crystal size is large but has uneven surface texture, whereas at $120^{\circ} \mathrm{C}-24$ hours of MOF-5 crystal size large and flat enough surface texture, but there are cracks. The EDX results showed that treatment of $120^{\circ} \mathrm{C}-24$ hours is a treatment that has a composition wt\% $\mathrm{Zn}$ largest and most suited to the simulation of the code $\mathrm{D}$. It can be concluded that treatment with optimum conditions is $120^{\circ} \mathrm{C}-24$ hours.

\section{ACKNOWLEDGEMENT}

We gratefully acknowledge funding from Directorate General of Higher Education Indonesia.

\section{REFERENCES}

[1]. Cheng, S., Liu, S., Zhao, Q., Li, J., "Improved Synthesis and Hydrogen Storage of a Microporous Metal-Organic Framework Material,” Energy Conversion and Management, vol. 50, pp. 1314-1317, 2009.

[2]. Blanita, G., Ardelean, O., Lupu, D., Borodi, G., Coros, M., Vlassa, M., Misan, I., Coldea, I., Mihet, M., Popeneciu, G., "Microwave Assisted Synthesis of Mof-5 at Atmospheric Pressure”, Rev. Roum. Chim., vol. 56, pp. 583-588, 2011.

[3]. Sumida, K., Arnold, J., "Preparation, Characterization, and Postsynthetic Modification of Metal-Organic Frameworks: Synthetic Experiments for an Undergraduate Laboratory Course in Inorganic Chemistry”, Journal of Chemical Education, vol. 88, pp. 92-94, 2011.

[4]. Son, W. J., Kim, J., Kim, J., Ahn, W. S., "Sonochemical Synthesis of MOF-5”, Chem. Commun., vol. 65, pp. 63366338, 2008

[5]. Li, J., Cheng, S., Zhao, Q., Longa, P., Donga, J., "Synthesis and Hydrogen-Storage Behavior of Metal-Organic Framework MOF-5”, International Journal of Hydrogen Energy, vol. 34, pp. 1377 - 1382, 2009.

[6]. Xiao, B., Yuan, Q., "Nanoporous Metal Organic Framework Materials for Hydrogen Storage”, Particuology, vol. 7, pp. 129140, 2009.

[7]. Biemmi, E., Christian, S., Stock, N., Bein T., "High-Throughput Screening of Synthesis Parameters in The Formation of The Metal-Organic Frameworks MOF-5 and HKUST-1", Microporous and Mesoporous Materials, vol. 117, pp. 111-117, 2009.

[8]. Lu, C. M., Liu, J., Xiao, K., Harris, A. T., "Microwave Enhanced Synthesis of MOF-5 and its CO2 Capture Ability at Moderate Temperatures Across Multiple Capture and Release Cycles”, Chemical Engineering Journal, vol. 156, pp. 465-470, 2010.

[9]. Phan, N. T.S., Le, K. A., Phan, T. D., "MOF-5 as an Efficient Heterogeneous Catalyst for Friedel-Crafts Alkylation Reactions”, Applied Catalysis A: General, vol. 382, pp. 246253, 2010.

[10]. Zhao, Z., Ma, X., Li, Z., Lin, Y. S., “Synthesis, Characterization and Gas Transport Properties of MOF-5 Membranes”, Journal of Membrane Science, vol. 382, pp. 82-90, 2011.

[11]. Orefuwa, S. A., Yang, H., Goudy, A. J., "Rapid Solvothermal Synthesis of an Isoreticular Metal-Organic Framework with Permanent Porosity for Hydrogen Storage”, Microporous and Mesoporous Materials, vol. 153, pp. 88-93, 2012.

[12]. Venna, S. R., Jasinski, J. B., Carreon, M. A., "Structural Evolution of Zeolitic Imidazolate Framework-8”, Journal of American. Chemistry. Society, vol. 132, pp. 18030-18033, 2010.

[13]. Choi, J. S., Son, W. J., Kim, J., Ahn, W. S., "Metal-Organic Frameworks MOF-5 Prepared by Microwave Heating: Factors to be Considered”, Microporous and Mesoporous Materials, vol. 116, pp. 727-731, 2008.

[14]. Kida, K., Okita, M., Ito, Y., Tanaka, S., Miyake, Y., "Preparation and Size Control of ZIF-8 Particles in Aqueous Solution”, The Royal Society of Chemistry 
[15]. Zhang, L., Hu, Y. H., “Observation of ZnO Nanoparticles Outside Pores of Nano Zn Metal-Organic Framework”, Physics Letters A, vol. 375, pp. 1514-1517, 2011

[16]. Zhang, L., Hu, Y. H., "Structure Distortion of Zn4O13C24H12 Framework (MOF-5)”, Materials Science and Engineering B, vol. 176, pp. 573-578, 2011

[17]. Jiang, H. L., Liu, B., Lan, Y. Q., Kuratani, K., Akita, T. Shioyama, H., Zong, F., Xu, Q., "From Metal-Organic Framework to Nanoporous Carbon: Toward a Very High
Surface Area and Hydrogen Uptake”, J. Am. Chem. Soc., vol. 133, pp. 11854-11857, 2011

[18]. Yang, S.J., Kim, T., Im, J.H., Kim, Y.S., Lee, K., Jung, H., Park., C.R., "MOF-Derived Hierarchically Porous Carbon with Exceptional Porosity and Hydrogen Storage Capacity", Chem Mater, vol. 24, pp. 464-470. 2012

[19]. Mueller, U., Schubert, M., Teich, F., Puetter, H., Arndt K. S., Pastre', J., "Metal-Organic Frameworks - Prospective Industrial CentreApplications”, J. Mater. Chem., vol. 16, pp. 626-636, 2006.

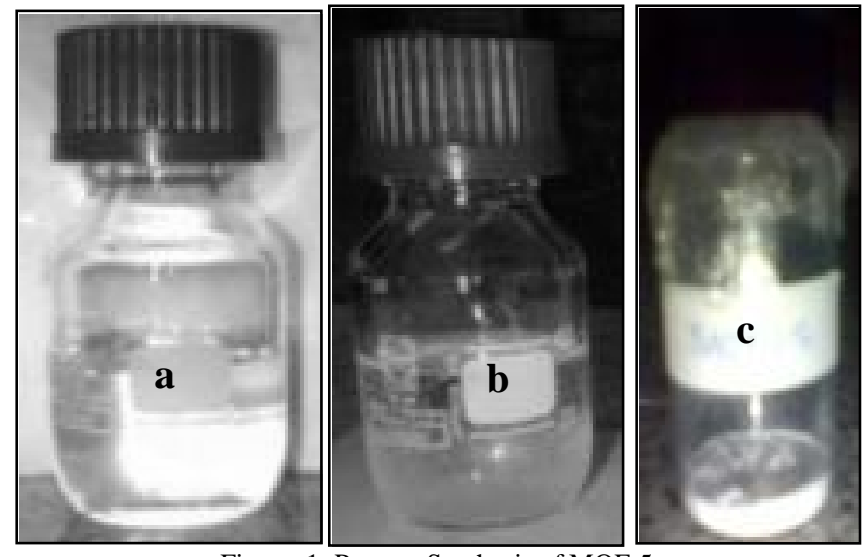

Figure. 1. Process Synthesis of MOF-5

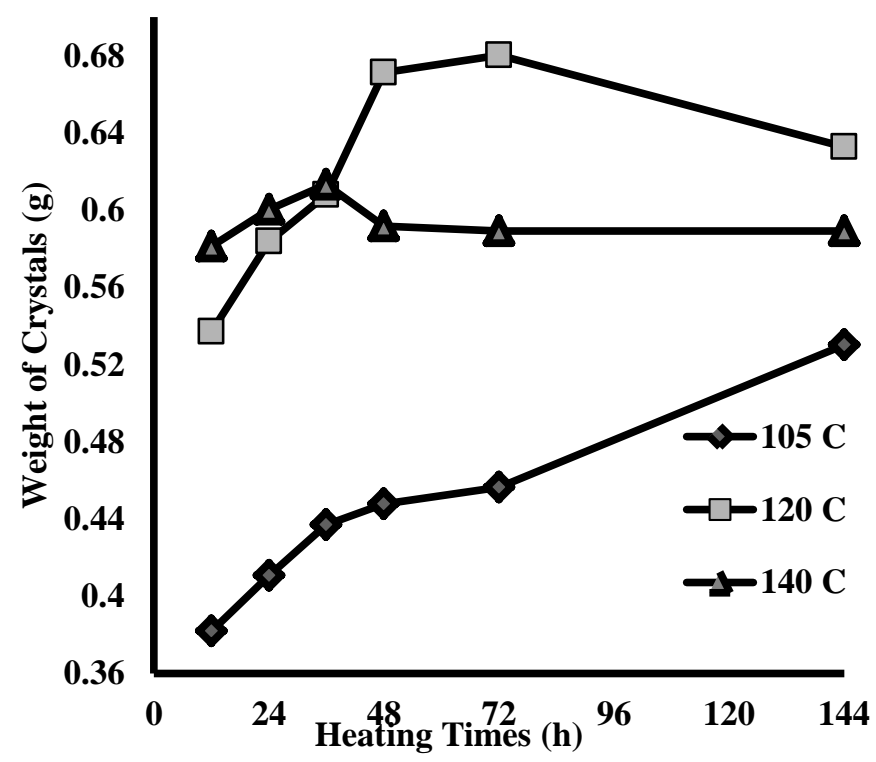

Figure 2. Corelation Between Mass Changes and Temperature Function of MOF-5

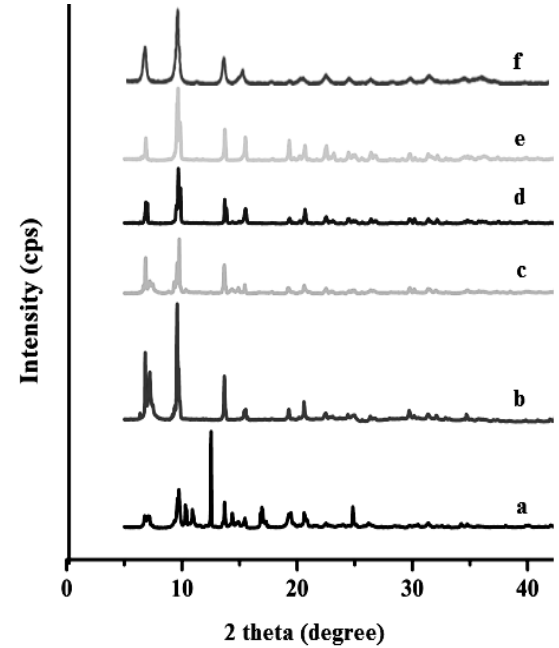

Figure 3. Diffraction Patterns of MOF-5 at $105^{\circ} \mathrm{C}$ and Different

Time Function: a. 12 h, b. 24 h, c. 36 h, d. 48 h, e. 144h, f.

Simulated MOF-5

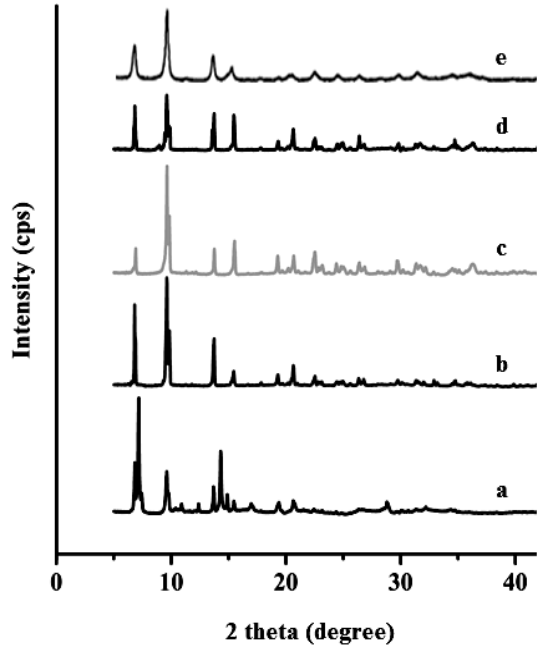

Figure 4. Diffraction Patterns of MOF-5 at $120^{\circ} \mathrm{C}$ and Different Time Function: a. 12 h, b. 24 h, c. 48 h, d. 144 h, e. Simulated MOF-5 


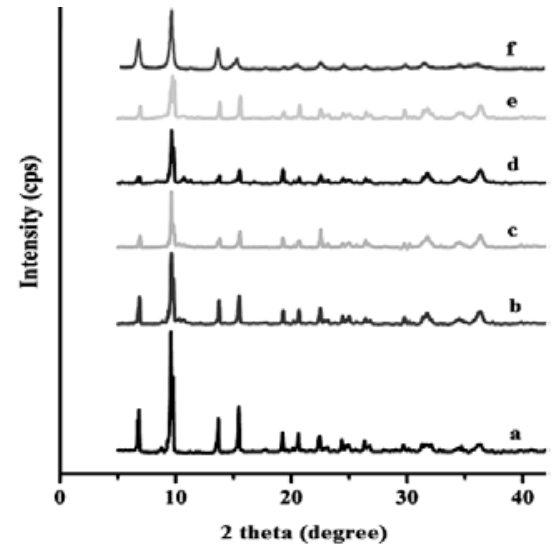

Figure 5. Diffraction Patterns of MOF-5 at $140{ }^{\circ} \mathrm{C}$ and Different Time Function: a. 12 h, b. 24 h, c. 36 h, d. 72 h, e. 144h, f. Simulated MOF-5

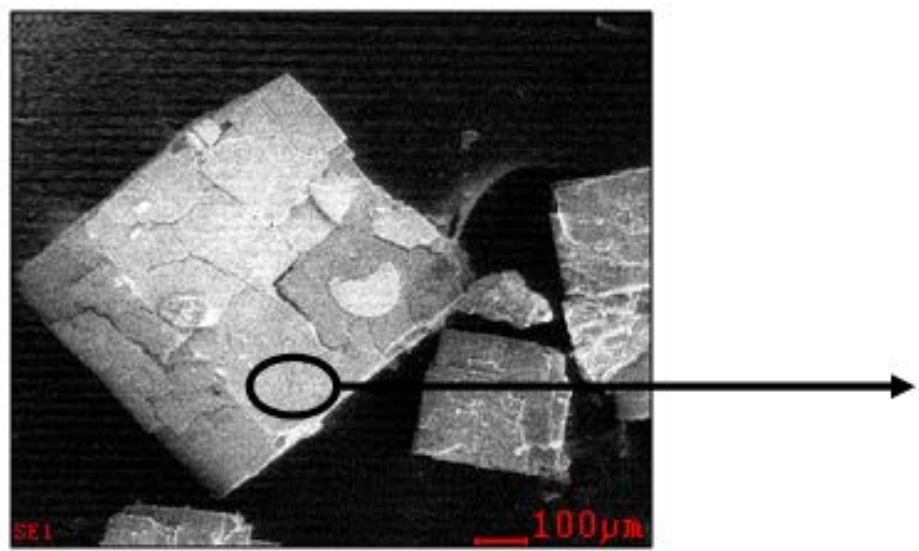

Figure. 8 SEM-EDX Images of MOF-5 at $105^{\circ} \mathrm{C}-144 \mathrm{~h}$


Figure. 9 SEM-EDX Images of MOF- 5 at $120^{\circ} \mathrm{C}-24 \mathrm{~h}$

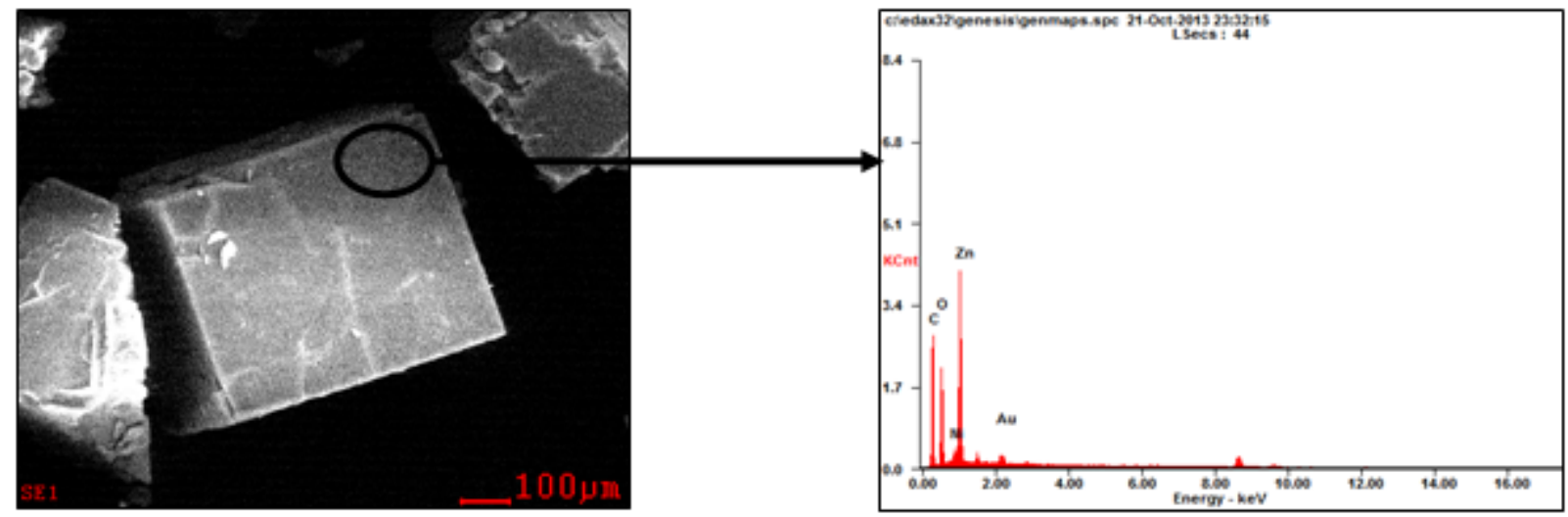

Figure. 10 SEM-EDX Images of MOF- 5 at $140^{\circ} \mathrm{C}-12 \mathrm{~h}$ 
TABLE 1.

PEAK AREA AND CRystalLINITY OF MOF-5 AT OPTIMUM REACTION CONDITIONS

\begin{tabular}{cccc}
\hline \hline Cystals & $\begin{array}{c}\text { Conditions of } \\
\text { Synthesis }\end{array}$ & Peak Area & $\begin{array}{c}\text { Crystallinity } \\
(\%)\end{array}$ \\
\hline A & $105^{\circ} \mathrm{C}-144 \mathrm{~h}$ & 4940,07 & 91,37 \\
B & $120^{\circ} \mathrm{C}-24 \mathrm{~h}$ & 5406,46 & 100 \\
C & $140^{\circ} \mathrm{C}-12 \mathrm{~h}$ & 3840,16 & 71,03 \\
\hline \hline
\end{tabular}

